\title{
Effect of Preemptive Clonidnine Versus Pethidine and Ketamine on Postoperative Shivering During Spinal Anesthesia
}

\author{
Mahshid Ghasemi ${ }^{1}$, Faranak Behnaz ${ }^{1} \&$ Massumeh Hashemi Mad $^{2}$ \\ ${ }^{1}$ Anesthesiology Research Center, Shahid Beheshti University of Medical Sciences, Tehran, Iran \\ ${ }^{2}$ Anesthesiologist of Shahid Beheshti University Medical Sciences, Tehran, Iran \\ Correspondence: Faranak Behnaz, Anesthesiology Research Center, faculty of medicine, Shahid Beheshti \\ University of Medical Sciences, Tehran, Iran. Email: Faranak.Behnaz@gmail.com
}

Received: October 2, 2017

Accepted: October 19, 2017

Online Published: October 31, 2017

doi:10.5539/jmbr.v7n1p156

URL: https://doi.org/10.5539/jmbr.v7n1p156

\begin{abstract}
Introduction: Postoperative Shivering is an early postoperative complication. Incidence of postoperative shivering (POS) following surgeries varies between 20 to $60 \%$. There is still no consensus on treatment modalities especially in opioid-dependent patients. Aim: To compare the effect of preemptive clonidine, ketamin and pethidine in controlling postoperative shivering in addicted patients who undergo spinal anesthesia. Methods: In a clinical trial, 81 patients who underwent spinal anesthesia for elective orthopaedic surgery for lower limb were enrolled and assigned to groups of 27 patients of the study based on accidental numbers, and 2 patients in Pethidine group and 2 patients in ketamine group were excluded from the study. Clonidine $2 \mathrm{mg}$ was administered orally prior to surgery. Ketamin $2 \mathrm{mg} / \mathrm{kg}$ and pethidine $0.5 \mathrm{mg} / \mathrm{kg}$ were administered in recovery to the patients. Postoperative shivering was measured in patients during stay in post anethesia care unit. Blood pressure and heart rate was recorded during 30 minutes after spinal anethesia in operating room. Results: No significant differences in blood pressure and heart rate were observed between patients. Incidence of postoperative shivering was $28 \%$ in clonidine, $36 \%$ in pethidine and $48 \%$ in ketamin group. Risk of shivering was significantly reduced in patients received clonidine in compare to ketamine (RR: $0.34,95 \% \mathrm{CI}: 0.138-0.856, \mathrm{p}=0.022$ ) which was significant and compare to pethidine $(\mathrm{RR}=0.79,95 \% \mathrm{CI}: 0.272-2.323, \mathrm{p}=0.67)$ which was not significant. Conclusion: preemptive Clonidine has superior effect compare to postoperative ketamin and pethidine in controlling postoperative shivering.
\end{abstract}

Keywords: Clonidnine, ketamine, Pethidine, Postoperative, Shivering, Spinal Anesthesia

\section{Introduction}

Postoperative shivering (POS) is an early postoperative complication following spinal anesthesia. Postoperative shivering incidence has been reported between 20 to 60\% (Manninen, Raman, Boyle, \& el-Beheiry, 1999). Hypothermia is a common finding during anesthesia. General anesthesia could significantly impact thermoregulatory process. Ppostoperative shivering in general anesthesia is mainly induced by hypothermia while thermoregulation is deeply suppressed by anesthetics (Zhang \& Wong, 1999). Shivering enhances metabolic heat production upto $50 \%$ to $100 \%$ in adults. However, this increase is not effective during general anethseia compare to severe heat loss (Eberhart et al., 2005).

Preventive pharmacologic therapies are alternative treatment for post-operative shivering (Mahmood \& Zweifler, 2007). Non-pharmacologic approaches such as maintaining room temperature, warmers and air blankets (H. Y. Kim et al., 2014) and hot intravenous infusions have variable effect (Alfonsi, 2003). Duration of anesthesia is a risk factor for POS (Crossley, 1992). POS could increase myocardial oxygen consumption and cardiovascular events.

Although the wax-and-wane pattern of post shivering is a thermoregulatory response to intraoperative hypothermia; however; neurotransmitter pathways playing role in POS are poorly understood. POS may result from disinhibition of normal cortical control of spinal reflexes induced anesthesia.

Many drugs are introduced as treatment for POS including pethidine, clonidine, and physostigmine. Opioids, alpha 2-adrenergics (Hwang, 2014), Ketamine (Dal et al., 2005), and anticholinergics are other choices. Other drugs such as Tramadole (Heid et al., 2008), Nefopam (Rosa et al., 1995), Ketanserin a 5-HT2 antagonist has also been 
used for prevention of POS (Y. A. Kim et al., 2013). Although Tramadole and Pethidine are available drugs for prevention of POS, however, both drugs could increase intra cranial pressure (ICP) and increase risk of seizure. Clonidine is an $\alpha 2$-agonist with both central and peripheral effect (Eisenach, De Kock, \& Klimscha, 1996). It passes the blood brain barrier and reaches the hypothalamus and medulla. It decreases the excitatory sympathetic neuron impulses.

\subsection{Objectives}

To compare the Effect of Clonidnine, ketamine and Pethidine on postoperative shivering during Spinal Anesthesia.

\section{Methods}

\subsection{Ethics Declaration}

The study was reviewed and approved by the University of Medical Sciences Ethics Committee. All procedures performed in this study were in accordance with the ethical standards of the institutional research committee. Information about the study was given comprehensively both orally and in written form to all patients or their accompanying adult. They gave their informed written consents prior to their inclusion in the study.

\subsection{Patient Selection}

In a double-blinded randomized clinical trial study, 81 patients who underwent spinal anesthesia for elective orthopaedic surgery for lower limb were enrolled and assigned to groups of 27 patients of the study based on accidental numbers selected by a computer, and 2 patients in Pethidine group and 2 patients in ketamine group were excluded from the study. Patients and the doctors involved in the study were blinded to the group of patient.

Total of 81 patients with ASA class I to II, age between 20 to 60 years, BMI less than $30 \mathrm{~kg} / \mathrm{m}^{2}$, no history of hyper or hypothyroidism or Parkinson's disease, and scheduled for elective lower extremity surgery were included in the study. Patients were divided to receive clonidine, ketamine, and pethidine. Patients were excluded if they had perioperative fever (temperature $>38$ ), received blood transfusion more than 4 units of pack cells, or used medications to alter thermoregulation during surgery.

\subsection{Study Design}

This study was designed as a double blinded randomized clinical trial. Randomization was performed based on accidental numbers assigned to each patient by computer. Anesthesiologists performing evaluation were blinded to the group of patient. Patients were also blinded to the drug that was administered. Drugs were also delivered in the same size syringe and same color to the anesthesiologist performing spinal anesthesia (concealment allocation). Duration of study was 1 year period from March 2014 to June 2015.

Eighty one patients were enrolled in the study and assigned to groups of 27 patients; group Clonidine, Ketamine, and Pethidine. Two patients in Pethidine group and 2 patients in ketamine group were excluded from the study. Anesthesiologist administering drug was not aware of group of patient and syringe content (allocation concealment). Besides, physician who evaluated the shivering and other monitoring were not aware of group of patient.

Clonidine $0.2 \mathrm{mg}$ oral was administered 1 hour before surgery. Ketamine $2 \mathrm{mg} / \mathrm{kg}$ and Pethidine $0.5 \mathrm{mg} / \mathrm{kg}$ was administered after surgery in recovery room.

\subsection{Method of Anesthesia}

Spinal anesthesia was performed by patient in sit position, and L3-4 space, needle G25, and Bupivacaine isobaric $0.5 \% 4 \mathrm{ml}$ equal to $20 \mathrm{mg}$ was injected into sub-arachnoid space,

Patients were covered with 3 layers of surgical drapes. The ambient temperature was measured and set by a wall thermometer to room temperature at $23 \mathrm{C}$.

\subsection{Data Collection}

Demographic variables were recorded in specified data sheet for all patients. Heart rate and blood pressure were recorded during surgery. Presence of shivering in recovery was also recorded as positive or negative.

\section{Results}

In this study, total numbers of 81 patients were enrolled and 2 patients in Pethidine group and 2 patients in ketamine group were excluded from the study. The age was significantly higher in pethidine group but was not significantly different between ketamine and clonidine group. Axillary temperature was measured between 36.5-37.5 C degrees in all patients (100\% of patients) in three groups of study (Table 1). 
Table 1. Comparison of age, opioid abused and patients with normal axillary temperature

\begin{tabular}{lllll}
\hline & $\begin{array}{l}\text { Clonidine } \\
\mathbf{N = 2 5}\end{array}$ & $\begin{array}{l}\text { Pethidine } \\
\mathbf{N = 2 5}\end{array}$ & $\begin{array}{l}\text { Ketamin } \\
\mathbf{N = 2 7}\end{array}$ & P-value \\
\hline $\begin{array}{l}\text { Age } \\
\text { Type of opioid }\end{array}$ & $34.52 \pm 10.15$ & $44.48 \pm 12.22$ & $39.85 \pm 15.48$ & 0.028 \\
Synthetic & & & & \\
Semi-synthetic & $0(0 \%)$ & $4(16.7 \%)$ & $8(34.8 \%)$ & \\
Naturally & $5(20.0 \%)$ & $4(16.7 \%)$ & $2(8.7 \%)$ & \\
Amphetamine & $19(76.0 \%)$ & $10(41.7 \%)$ & $10(43.5 \%)$ & 0.005 \\
Unknown & $1(4.0 \%)$ & $6(25.0 \%)$ & $3(13.0 \%)$ & \\
Axiliary temperature 36.5-37.5 & 0 & 1 & 4 & \\
\hline & $25(100 \%)$ & $25(100 \%)$ & $27(100 \%)$ & NA \\
\hline
\end{tabular}

Systolic blood pressure and diastolic blood pressure were not significantly different at various time points between three groups of study $(\mathrm{p}>0.05)$ in ANOVA analysis. Heart rate was not significantly different at various time points between three groups of study. Oxygen saturation was not also significantly different at various time points between three groups of study (Figure 1).

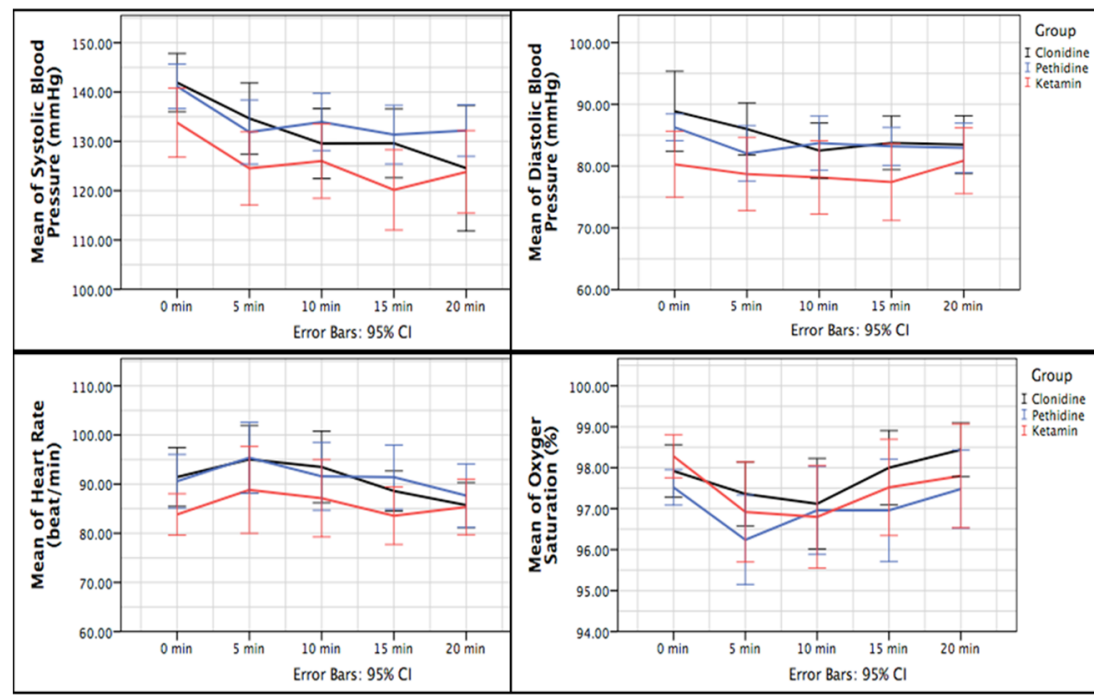

Figure 1. Trend of systolic and diastolic blood pressure, heart rate, and oxygen saturation in post-operative time points

Percentage of patients with post-operative shivering was lower in clonidine group compare to ketamine and pethidine groups but it was not significant (Table2).

Table 2. Post-operative shivering in three groups of study

\begin{tabular}{lllll}
\hline Shivering & Clonidine & Pethidine & Ketamin & P-value \\
\hline $\mathbf{0}$ min & $1(4.0 \%)$ & $1(4.0 \%)$ & $2(7.4 \%)$ & $>0.999$ \\
$\mathbf{5}$ min & $6(24.0 \%)$ & $9(36.0 \%)$ & $11(40.7 \%)$ & 0.425 \\
$\mathbf{1 0} \mathbf{~ m i n}$ & $6(24.0 \%)$ & $8(32.0 \%)$ & $10(37.0 \%)$ & 0.594 \\
$\mathbf{1 5} \mathbf{~ m i n}$ & $3(12.0 \%)$ & $6(24.0 \%)$ & $7(25.9 \%)$ & 0.414 \\
$\mathbf{2 0} \mathbf{m i n}$ & $0(0.0 \%)$ & $3(12.0 \%)$ & $4(16.0 \%)$ & 0.150 \\
Post-operative & $7(28.0 \%)$ & $9(36.0 \%)$ & $13(48.1 \%)$ & 0.319 \\
\hline
\end{tabular}

In a GEE (Generalized Estimating Equations) model analysis the relative risk (RR) of shivering was 0.36 times in clonidine compare to ketamine and was 0.63 times in clonidine compare to pethidine group. When adjusted for age, RR of shivering was 0.34 times in clonidine compare to ketamine and was 0.79 times in clonidine compare to pethidine group (Table3). 
Table 3. Generalized Estimating Equations (GEE) analysis the relative risk (RR) of shivering

\begin{tabular}{lll}
\hline GEE for Shivering & P-value & RR \\
\hline Non-adjusted & & \\
Clonidine/Ketamin & 0.033 & $0.369(0.148-0.921)$ \\
Pethidine/Ketamin & 0.621 & $0.781(0.293-2.079)$ \\
Clonidine/Pethidine & 0.394 & $0.637(0.226-1.795)$ \\
Adjusted for Age & & \\
Clonidine/Ketamin & 0.022 & $0.344(0.138-0.856)$ \\
Pethidine/Ketamin & 0.620 & $0.765(0.264-2.210)$ \\
Clonidine/Pethidine & 0.675 & $0.795(0.272-2.323)$ \\
Adjusted for Age \& Drug groups & & \\
Clonidine/Ketamin & 0.130 & $0.448(0.159-1.262)$ \\
Pethidine/Ketamin & 0.112 & $0.406(0.134-1.234)$ \\
Clonidine/Pethidine & 0.883 & $1.103(0.298-4.092)$ \\
\hline
\end{tabular}

\section{Conclusion}

Here in this study, we embarked on a shivering in peri and post-operative period in opioid-dependent patients. Shivering is one of the most common problems during and after spinal anesthesia. Treatment of shivering in opioid-dependent patients after spinal anesthesia is still controversial and needs further researches. Results of our study showed that clonidine has superior effect to ketamine and pethidine in controlling shivering in opioiddependent patients.

Clonidine is alpha-2-agonists that inhibit central sympathetic stimulation. Clonidine is orally administered and easy to use for preventive effect in shivering. Dexmedetomidine has been proved to have central effect on controlling shivering in patients (Liu et al., 2015). However, its effect in opioid-dependent patients has not been published previously. Unlike oral clonidine, Dexmedetomidine could induce profound hypotension and bradycardia when used intravenously.

Pre-operative clonidine is an appropriate choice in controlling post-operative shivering in opioid-dependent patients which start its preventive action prior to starting neuroaxial anesthesia. Mechanism of action for clonidine is through central decrease in threshold of temperature for shivering and vasoconstriction. In a systematic review by Kranke et al; they showed that clonidine, pethidine and ketanserin are appropriate pharmacological treatment of postoperative shivering (Kranke, Eberhart, Roewer, \& Tramer, 2002).

Pethidine has proven pharmacological effect on postoperative shivering through k-receptor; however, opioiddependent patients could have tolerance of opioid receptors including $\mathrm{k}$ receptor. This may explain lower effectiveness of pethidine in opioid-dependent patients compare to normal population. Ketamine has also effect on modulation of NMDA receptor function to decrease tolerance to opioids in opioid-dependent patients (Hollmann, Liu, Hoenemann, Liu, \& Durieux, 2001). However, ketamine effect on postoperative shivering is not far more than clonidine or Pethidine in opioid-dependent patients. Vice versa, Suzuki et el showed that perioperative ketamine increased the incidence of POS induced by remifentanil (Suzuki, Osumi, Shimada, \& Bito, 2013). Remifentanil-induced shivering is a model for opioid-dependent patients. This was consistent with our results that ketamine is not more effective in controlling shivering than pethidine in opioid-dependent patients.

Other studies such as Tewari et al (Tewari et al., 2014), evaluating the prophylactic efficacy of oral clonidine and tramadol for peri-operative shivering in geriatric patients undergoing transurethral resection of prostate; they showed that $5 \%$ in clonidine and $7 \%$ in tramadol group had shivering which there were no significant differences between two groups of study. In another similar study by Wason et al, prophylactic ketamine had no superior effect to clonidine and tramadol in controlling and decreasing POS (Wason, Jain, Gupta, \& Gogia, 2012). Interestingly, unlike clonidine in our study, Bhukal et al showed that low dose pethidine does not decrease incidence of postoperative shivering in laparoscopic surgeries (Bhukal, Solanki, Kumar, \& Jain, 2011). Recent publications have mentioned effect of preemptive Dopamine antagonist such as ondancetrone and granicetrone in decreasing post-operative shivering (Sagir et al., 2007; Teymourian et al., 2015).

In conclusion, pre-operative oral clonidine has a superior effect in controlling postoperative shivering compare to postoperative intravenous pethidine and ketamine in opioid-dependent patients. 


\section{References}

Alfonsi, P. (2003). Postanaesthetic shivering. Epidemiology, pathophysiology and approaches to prevention and management. Minerva Anestesiol, 69(5), 438-442.

Bhukal, I., Solanki, S. L., Kumar, S., \& Jain, A. (2011). Pre-induction low dose pethidine does not decrease incidence of postoperative shivering in laparoscopic gynecological surgeries. $J$ Anaesthesiol Clin Pharmacol, 27(3), 349-353. https://doi.org10.4103/0970-9185.83680

Crossley, A. W. (1992). Six months of shivering in a district general hospital. Anaesthesia, 47(10), 845-848.

Dal, D., Kose, A., Honca, M., Akinci, S. B., Basgul, E., \& Aypar, U. (2005). Efficacy of prophylactic ketamine in preventing postoperative shivering. Br J Anaesth, 95(2), 189-192. https://doi.org10.1093/bja/aei148

Eberhart, L. H., Doderlein, F., Eisenhardt, G., Kranke, P., Sessler, D. I., Torossian, A., ... Morin, A. M. (2005). Independent risk factors for postoperative shivering. Anesth Analg, 101(6), 1849-1857. https://doi.org10.1213/01.ANE.0000184128.41795.FE

Eisenach, J. C., De Kock, M., \& Klimscha, W. (1996). alpha(2)-adrenergic agonists for regional anesthesia. A clinical review of clonidine (1984-1995). Anesthesiology, 85(3), 655-674.

Heid, F., Grimm, U., Roth, W., Piepho, T., Kerz, T., \& Jage, J. (2008). Intraoperative tramadol reduces shivering but not pain after remifentanil-isoflurane general anaesthesia. A placebo-controlled, double-blind trial. Eur $J$ Anaesthesiol, 25(6), 468-472. https://doi.org10.1017/S0265021508003645

Hollmann, M. W., Liu, H. T., Hoenemann, C. W., Liu, W. H., \& Durieux, M. E. (2001). Modulation of NMDA receptor function by ketamine and magnesium. Part II: interactions with volatile anesthetics. Anesth Analg, 92(5), 1182-1191.

Hwang, S. M. (2014). Hypothermia, shivering, and dexmedetomidine. Korean J Anesthesiol, 66(5), 337-338. https://doi.org10.4097/kjae.2014.66.5.337

Kim, H. Y., Lee, K. C., Lee, M. J., Kim, M. N., Kim, J. S., Lee, W. S., \& Lee, J. H. (2014). Comparison of the efficacy of a forced-air warming system and circulating-water mattress on core temperature and postanesthesia shivering in elderly patients undergoing total knee arthroplasty under spinal anesthesia. Korean $J$ Anesthesiol, 66(5), 352-357. https://doi.org10.4097/kjae.2014.66.5.352

Kim, Y. A., Kweon, T. D., Kim, M., Lee, H. I., Lee, Y. J., \& Lee, K. Y. (2013). Comparison of meperidine and nefopam for prevention of shivering during spinal anesthesia. Korean J Anesthesiol, 64(3), 229-233. https://doi.org10.4097/kjae.2013.64.3.229

Kranke, P., Eberhart, L. H., Roewer, N., \& Tramer, M. R. (2002). Pharmacological treatment of postoperative shivering: a quantitative systematic review of randomized controlled trials. Anesth Analg, 94(2), 453-460, table of contents.

Liu, Z. X., Xu, F. Y., Liang, X., Zhou, M., Wu, L., Wu, J. R., ... Zou, Z. (2015). Efficacy of dexmedetomidine on postoperative shivering: a meta-analysis of clinical trials. Can $J$ Anaesth, 62(7), 816-829. https://doi.org10.1007/s12630-015-0368-1

Mahmood, M. A., \& Zweifler, R. M. (2007). Progress in shivering control. J Neurol Sci, 261(1-2), 47-54. https://doi.org10.1016/j.jns.2007.04.038

Manninen, P. H., Raman, S. K., Boyle, K., \& el-Beheiry, H. (1999). Early postoperative complications following neurosurgical procedures. Can J Anaesth, 46(1), 7-14. https://doi.org10.1007/BF03012507

Rosa, G., Pinto, G., Orsi, P., de Blasi, R. A., Conti, G., Sanita, R., ... Gasparetto, A. (1995). Control of post anaesthetic shivering with nefopam hydrochloride in mildly hypothermic patients after neurosurgery. Acta Anaesthesiol Scand, 39(1), 90-95.

Sagir, O., Gulhas, N., Toprak, H., Yucel, A., Begec, Z., \& Ersoy, O. (2007). Control of shivering during regional anaesthesia: prophylactic ketamine and granisetron. Acta Anaesthesiol Scand, 51(1), 44-49. https://doi.org10.1111/j.1399-6576.2006.01196.x

Suzuki, M., Osumi, M., Shimada, H., \& Bito, H. (2013). Perioperative very low-dose ketamine infusion actually increases the incidence of postoperative remifentanil-induced shivering-double-blind randomized trial. Acta Anaesthesiol Taiwan, 51(4), 149-154. https://doi.org10.1016/j.aat.2013.12.003

Tewari, A., Dhawan, I., Mahendru, V., Katyal, S., Singh, A., \& Narula, N. (2014). A comparative study evaluating the prophylactic efficacy of oral clonidine and tramadol for perioperative shivering in geriatric patients 
undergoing transurethral resection of prostate. J Anaesthesiol Clin Pharmacol, 30(3), 340-344. https://doi.org10.4103/0970-9185.137264

Teymourian, H., Mohajerani, S. A., Bagheri, P., Seddighi, A., Seddighi, A. S., \& Razavian, I. (2015). Effect of Ondansetron on Postoperative Shivering After Craniotomy. World Neurosurg, 84(6), 1923-1928. https://doi.org10.1016/j.wneu.2015.08.034

Wason, R., Jain, N., Gupta, P., \& Gogia, A. R. (2012). Randomized double-blind comparison of prophylactic ketamine, clonidine and tramadol for the control of shivering under neuraxial anaesthesia. Indian J Anaesth, 56(4), 370-375. https://doi.org10.4103/0019-5049.100821

Zhang, Y., \& Wong, K. C. (1999). Anesthesia and postoperative shivering: its etiology, treatment and prevention. Acta Anaesthesiol Sin, 37(3), 115-120.

\section{Copyrights}

Copyright for this article is retained by the author(s), with first publication rights granted to the journal.

This is an open-access article distributed under the terms and conditions of the Creative Commons Attribution license (http://creativecommons.org/licenses/by/4.0/). 